\title{
"We Are All in This Together": Integrated Health Service Plans in Ontario
}

Hy Eliasoph, Barry Monaghan, Rémy Beaudoin, Robert Cushman, Gwen DuBois-Wing, Marilyn J. Emery, W. Michael Fenn, Sandra J. Hanmer, Paul Huras, Mimi Lowi-Young, Pat Mandy, Jean Trimnell, Garry Switzer, Tony Woolgar and John Butler

Fourteen recently created local health integration networks (LHINs) are Ontario's approach to planning, coordinating, integrating and funding healthcare on a regional basis. Governed by appointed boards, LHINs are crown corporations that will move decisionmaking and accountability for health services closer to consumers and health service providers and that will also assist with system performance management. The mandate of LHINs is outlined in Ontario's Local Health System Integration Act, 2006 (Government of Ontario 2006), which forms the basis for creating LHINs to help ensure the delivery of stronger, locally planned healthcare.

LHINs produced their first major deliverable when they issued their integrated health service plans (IHSPs) in October 2006. This article reviews the experience of LHINs in meeting this challenge, outlines the process and outcome dimensions of IHSPs and discusses eight opportunities for LHINs as they act on the basis of their plans.

As the Toronto Central LHIN's IHSP states, "a plan without action is useless" (Toronto Central LHIN 2006). A mixture of community engagement and an unfolding role for LHINs will help them make the transition from just planning to planning that is accompanied by action. In April 2007, LHINs began taking on the job of allocating resources to most health services in their areas, guided by the policies of Ontario's Ministry of Health and Long-Term Care and by the results of the IHSPs. The allocation function includes development of service agreements between LHINs and agencies that receive allocations, specifying the conditions under which the allocations will be made.

\section{Precursors to the IHSPs}

Even before LHINs were created, the ministry initiated one-day workshops in late 2005 for stakeholders (primarily health service providers) across the province to generate priorities for consideration by LHINs. These led to the creation of working groups in each LHIN area that provided an initial view of what could be done to improve health service delivery.

Once created, LHINs invested considerable energy in developing their capacity to work with each other.
This involved the development of a common business model as well as a collective vision: "engaging, enabling and empowering people for health" (personal communications). It also involved the selection of LHIN chief executive officers (CEOs), not only on the basis of their ability to listen and lead within their respective areas but also based on specialized skills each CEO could offer to the provincial LHIN team as well as an aptitude for working as part of this team.

Early initial stakeholder involvement and development of LHINs' capacity to work as a team prepared LHINs for development of IHSPs based on community engagement and using a common framework derived from cross-LHIN co-operation. In short, these community-driven IHSPs were compatible - but not identical since they incorporated local assessments of needs and priorities.

As part of cross-LHIN teamwork, two key documents were produced early in the life of LHINs as guides to IHSP development:

- A province-wide template, the 
Roadmap to the Integrated Health Service Plan (Ontario Ministry of Health and Long-Term Care 2006b), was developed jointly by LHINs and the ministry. The template did not predetermine the actual findings of each LHIN. Instead, it specified the sources of information to be used in developing the IHSPs and the ways the information would be organized within each plan.

- Proposed Provincial LHIN Stakeholder Engagement Strategy Framework was developed by the Central LHIN as a resource document for consideration by all LHINs (Central LHIN 2005). Community engagement - an activity LHINs took on with enthusiasm - is considered an essential part of planning by all LHINs.

Each IHSP has a three-year time frame (2007-2008 to 2009-2010). Each LHIN will review and adjust its IHSP annually. As North East LHIN's Board Chair Mathilde Gravelle Bazinet stated, "We recognize that other priorities may be added as we continue discussions with community partners across Northeastern Ontario. More public consultation is a given, and is welcomed" (North East LHIN 2006).

After the plans were submitted to the ministry, LHINs conducted a comprehensive review of all 14 plans to examine similarities and differences among the planning processes and findings. The review included feedback from the senior directors of planning and community engagement in each LHIN in terms of what went well and what requires improvement and change in future planning.

\section{IHSP Processes}

The review showed that stakeholder engagement was a hallmark of IHSP development: "LHINs made significant overtures to local residents, stakeholders and providers. Analysis ... suggests that there were more than 1,200 consultations held across the province" (McNiven Consulting 2006). Three kinds of consultation were used in developing the IHSPs:

1. Events to which members of the general public were invited were held in several communities within each LHIN to maximize attendance across what are often vast geographical areas. These included round tables, town hall meetings and open houses.

2. Events to which specific populations were invited included sessions for francophone stakeholders and Aboriginal populations, sessions

held specifically for providers and health interest groups, and activities to reach out to members of provincial parliament and local government.

3. Groups (often a mix of consumers and providers) were created to examine issues such as services for the elderly, mental health and addictions and information technology. LHINs created these groups to focus on areas for system development put forward by the pre-LHIN workshops and working groups, although some groups were added as a result of additional stakeholder consultation that took place at the beginning of the development of IHSPs.

Table 1. Action strategies developed by LHINs to address their priorities

\begin{tabular}{|l|l|}
\hline Access and Accessibility Strategies to Address the Following: & \\
\hline Mental health and addictions & \\
Primary care and primary care linkages & \\
Seniors' services and seniors' health and wellness & \\
Transportation to and from care & \\
Emergency care & \\
Maternal and child services & \\
Long-term care services & \\
Critical care & \\
Acute care & \\
Specialists and specialty care & \\
Palliative and end-of-life care & \\
The frail elderly & \\
\hline Population Health Strategies to Address the Following: & \\
\hline Chronic disease prevention and management & \\
Health and wellness promotion & \\
\hline Diversity Strategies to Address the Following: & \\
\hline Aboriginal health and engagement with Aboriginal communities & \\
French language services & \\
Diverse ethnocultural populations & \\
\hline System Effectiveness Strategies to Address the Following: & \\
\hline Health human resources & \\
W-health times & \\
Back-office integration & \\
Innovative local solutions to provincial priorities in partnership with network providers & \\
An evidence-based approach to health services in an integrated health system & \\
\hline
\end{tabular}


All LHINs included the results of environmental scans in their IHSPs. All scans considered demographic characteristics, health status indicators, determinants of health and local trends and comparisons to the province as a whole.

\section{IHSP Outcomes}

Several common priorities emerged from the IHSPs, most notably access to primary care, services for mental health and addiction, chronic disease prevention and management and serving seniors. However, LHINs went beyond identifying priorities in their IHSPs. They also developed action strategies for their priorities, usually specifying actions to be taken in each of the three years covered by the IHSPs. The most common action strategies are listed in Table 1, based on four categories used in the IHSP review.

Not every LHIN developed an action strategy for each of these service issues, in large measure because, in some LHINs, integrated planning and service delivery for a particular service issue are already sufficiently developed that a formal action strategy is not necessary. In these instances, LHINs will continue to support the good work already under way.

\section{Areas for Evolution of LHIN Planning}

The review of IHSPs identified opportunities for planning to evolve, building on success to date, including the following:

- Exploring ways to more fully engage Aboriginal communities in planning

- Exploring the identification of champions for change in their communities (an approach used successfully by a number of LHINs)

- Making maximum use of existing local planning and liaison processes

- Continuing to improve the database available to LHINs, specifically through data for population units smaller than an entire LHIN area; this requires close collaboration between LHINs and the ministry since much of the data are provided by the ministry

- Developing common terminology to describe elements of their planning

- Evaluating health services

Eight Opportunities for LHINs and Their Communities

Eight opportunities for LHINs and their communities to build on the IHSPs have already been discussed within and among LHINs. They are reflected in IHSPs and are outlined below.

\section{Ensuring Coherence between Provincial Planning and LHIN Planning}

By legislation, LHINs must plan in accordance with the minister of Health and Long-Term Care's provincial strategic healthcare plan. While LHINs prepared IHSPs in the absence of a provincial strategic plan, they were aware of the ministry's draft strategic priorities.

In December 2006, the ministry announced a province-wide consultation process leading to the release of a strategic plan in the spring of 2007. This provincial plan will be linked to IHSPs because, in the words of the ministry's media release announcing the consultation process, the plan will "build on the advice received by the 14 Local Health Integration Networks during earlier discussions with providers and citizens" (Ontario Ministry of Health and Long-Term Care 2006a).

The ministry's consultation process and strategic plan will in turn expedite future LHIN planning by making the ministry's priorities even more explicit, and giving LHINs the opportunity to develop system improvement targets that are consistent with the targets in the provincial plan.

\section{Maintaining the Planning Momentum}

Maintaining the planning momentum will be guided by four ongoing planning needs:

1. The need to translate planning assumptions and implementation plans into action

2. The need to help with the transition from planning to resource allocation by LHINs (including the need to demonstrate to members of the public and to providers that their contributions to planning have influenced allocations and linkages)

3. The need to determine how and when LHINs will adjust their plans so that revised year two and year three components, and an added year four component, are developed based on more in-depth information, knowledge and experience

4. The need to maintain and adjust community engagement strategies as key components of ongoing planning.

All four needs will in turn be influenced by the need to ensure coherence between provincial planning and LHIN planning.

Maintaining momentum involves the content of planning, but it also involves resources to conduct planning. It is here that LHINs are beginning to show
Early initial stakeholder involvement and development of LHINs' capacity to work as a team prepared LHINs for development of IHSPs based on community engagement and using a common framework derived from cross-LHIN co-operation. 
an innovative edge through community engagement and network-building activities that maximize community planning resources.

It is significant that LHINs are called local health integration networks rather than authorities. As Mimi Lowi-Young, CEO of the Central West LHIN, said, "Health care is a team effort. Good health care is built on partnerships and relationships with families, patients, providers, and government. We are all in this together. We must remember that this LHIN will function best when everyone contributes, when everyone knows what to expect, and when everyone is encouraged to tell us what needs to be done" (M. Lowi-Young, personal communication, 2006). This approach, shared by all LHINs, is the foundation for LHINs to serve as listeners, coaches and facilitators in planning that engages consumers, families, providers and the public in creating change, and that fosters shared accountability for improving outcomes.

\section{Building Service Delivery Partnerships}

The network approach goes beyond planning, as Lowi-Young's comment demonstrates. LHINs envision the integration of service delivery (another key word in the very name of LHINs) as a strategy driven by co-operative network-based endeavours rather than command-and-control approaches. Many IHSPs, for example, identify existing networks in their communities that can be supported and strengthened for planning or service delivery. Many IHSPs also propose the creation of additional local issue-specific or population-specific networks within the next three years.

Some stakeholders already embrace the network approach (and did so before LHINs were created). Others may be reluctant, waiting for evidence that incentive systems will reward collaboration rather than competition.
LHINs can help create these incentive systems through their resource allocation function and through their role in developing service agreements (which can specify that health service providers will act as network members as a condition for funding). LHINs can also create incentives by recognizing and supporting network champions.

Other stakeholders may be hesitant because they have not had opportunities to work together in the past and are therefore not familiar with each other's roles and scope of service. Providing them with opportunities and incentives for networked service delivery will help overcome this hesitance.

The LHIN mandate covers much of the healthcare system, but some services such as primary care (with the exception of community health centres) and public health units are not included. As well, the LHIN mandate does not include supportive services and systems that lie outside the health system. However, to improve health and healthcare outcomes, LHINs will need to engage, influence and be influenced by all healthcare sectors as well as by other human services. LHINs invited many other sectors and ministries to participate in stakeholder engagement activities during the IHSP development process, and many accepted the invitations with much enthusiasm.

LHINs have the ability and the will to engage other key sectors (including the health promotion sector, now under the Ministry of Health Promotion). IHSPs identify key areas where influence with other sectors is important. Many LHINs developed strategies in their IHSPs for primary care and primary care linkages, for instance, for health and wellness promotion and for transportation - areas not covered by the LHIN mandate.

LHINs will exert influence with these sectors through collaboration with the agencies, ministries and levels of government responsible for these sectors. As Sandra Hanmer, CEO of the Waterloo Wellington LHIN, commented, "Many of our priorities will require collaboration and co-operation with not only the Ministry of Health and Long-Term Care but with the Ministry of Community and Social Services, the Ministry of Children and Youth Services, the Ministry of Health Promotion, the Ministry of Colleges, Universities and Training, the Ministry of Education, the Ministry of Housing and the Ministry of Transportation to name just a few" (S.J. Hanmer, personal communication, 2006).

Continued and enhanced co-operation across LHINs is another important area for partnership, for the following reasons:

- Issues common to most or all LHINs can best be addressed using the synergy that emerges from joint thinking and action by LHINs.

- Populations in many LHINs rely heavily on services located outside their own LHINs. Some specialized services and resources are available only in a few locations in Ontario but are used by populations from all LHIN areas (e.g., tertiary pediatric services).

- Co-operation fosters the sharing of best practices and planning resources so that successful strategies do not need to be reinvented.

- Cross-LHIN co-operation demonstrates the collaborative behaviour that LHINs and their communities expect health service providers to exhibit.

Cross-LHIN partnerships emerged even before IHSPs were developed. This teamwork continued during the development of IHSPs. For instance, the North East and North West LHINs worked collectively to advance a Northern Ontario E-Health Information and Communication Technology Blueprint, and the five Greater Toronto 
Area (GTA) LHINs met with the GTA Rehabilitation Network to discuss crossLHIN collaboration and initiatives. Based on success to date, cross-LHIN collaboration will continue to grow in the future.

\section{Influencing Expectations}

The success of IHSP development through extensive community engagement raises community expectations. While not all participants may have been satisfied with their involvement, many welcomed the opportunity to generate views of a better future rather than accommodating themselves to someone else's view of a truncated future. As the Central East LHIN's website expressed, "Optimism abounds" (Central East LHIN 2007) - more than a slogan since good planning generates optimism.

For LHINs, influencing expectations so that they fit within available resources, while making the best use of available resources to improve health, is a crucial opportunity for maintaining pragmatic optimism. Influencing expectations involves making it clear that LHINs as discrete organizations with finite staff complements have limitations on how fast and far they can move - but defining LHINs as networks, with the expectation that all network members will contribute toward achieving goals, is a key way to influence expectations.

There will also be a need to address "magic bullet" expectations - the belief, for instance, that the ministry will provide vast sums of new money to underwrite changes proposed in IHSPs. While there may be some new money, most resources to create change will likely be found within existing allocations of funding and within the current authority possessed by LHINs.

\section{Creating the Incentives for Change}

Some savings may be achieved through network-based integration to provide resources that can be applied as an

\section{There will be a need to address "magic bullet" expectations - the belief, for instance, that the ministry will provide vast sums of new money to underwrite changes proposed in IHSPs.}

incentive for change. For example, many IHSPs include strategies for backoffice integration.

Modest new funding from the ministry is another potential incentive for change. As the next section suggests, any such funds will likely be used to maximize leverage for change.

In addition to funding, LHINs will use their capacity to create and support behavioural change as a way to produce a more integrated and effective healthcare system. This includes LHINs' ability to specify system-oriented activities in service agreements with health service providers that receive LHIN funding. Service providers may welcome such requirements once they observe that the new approach championed by LHINs rewards people who build bridges rather than empires.

\section{Using the Incentives for Change}

Leveraging - finding instances in which the greatest payoff in terms of enhanced health comes from the least investment of new or reallocated funds - will be a major opportunity for LHINs as they turn IHSPs into detailed plans for change. IHSPs began the process by identifying ways to maximize investment: by building on existing successful networks, by exploring back-office integration, by establishing partnerships within and beyond the healthcare system, and by improving information available to consumers and their navigators to maximize efficient, appropriate, timely and effective service use.

\section{Maintaining LHINs as Learning Organizations}

LHINs are becoming learning and knowledge dissemination organizations. They benefit from knowledge about integration successes and failures in other provinces that have pursued regionalization. More importantly, they have developed a commitment to teamwork and joint problem solving that helps them to learn from each other and from their communities, and to develop joint knowledge dissemination strategies.

Some LHINs have already initiated knowledge dissemination events (e.g., the Breakfast of Champions sessions hosted by the Central LHIN). Since knowledge also drives change, LHINs will initiate more such events in the future.

\section{Developing the Capacity for Evaluation}

Evaluating health services was not meant to be part of IHSP development. However, the experience of LHINs in developing IHSPs gives them a head start on the development and application of service evaluation standards and practices. They have now built relationships with health service providers that will help them understand current and emerging expectations that providers have of each other. As well, cross-LHIN co-operation honed during IHSP preparation makes them better able to develop common approaches to evaluation. And within each LHIN, the experience of planning teams and performance teams pulling together to develop implementable plans provides the basis for the development of joint evaluative activity by these teams.

Given the importance of networks as a way to create system integration, LHINs will also involve themselves in evaluating existing networks for planning and service delivery. This will help communities to identify high- 


\section{"LHIN-like" behaviour is best exemplified by a talent for speaking differently and hearing better, rather than arguing well.}

performance planning and service networks and to make their existing networks more effective and productive - important considerations in light of the amount of time and energy stakeholders invest in the network approach to change. Some LHINs have already begun the network evaluation process by identifying existing formal and informal networks.

\section{Concluding Observations}

The IHSP development process, characterized by cross-LHIN co-operation and community engagement, has produced plans using a number of common methodologies and producing implementation strategies for many similar priorities, while still reflecting the uniqueness of each LHIN. The results of the IHSP process will help LHINs to pursue eight opportunities that have a common feature linking them: they all require collaboration so that opportunity can become reality.

LHINs will succeed only as a collective, not as a disparate group of corporate entities. Practising "LHINlike" behaviour will be essential to this success. This behaviour is best exemplified by a talent for speaking differently and hearing better, rather than arguing well. If LHINs are to meet their challenges, they will need to be catalysts and instruments of change, on the premise - stated well in the Hamilton Niagara Haldimand Brant IHSP - that "relationships are the new accountability. No one person, stakeholder or provider organization is alone responsible for health system improvement" (Hamilton Niagara Haldimand Brant LHIN 2006).

The journey has only begun. But the first few steps, including the development of IHSPs, have charted a new course for the health system in Ontario.

\section{About the Authors \\ Hy Eliasoph, MA, CHE, is chief executive officer of the Central LHIN.}

Barry Monaghan, BComm, DHA, CHE, is chief executive officer of the Toronto Central LHIN.

Rémy Beaudoin, MPA, is chief executive officer of the North East LHIN.

Robert Cushman, MD, FRCPC, is chief executive officer of the Champlain LHIN.

Gwen DuBois-Wing, RN, MA, MHA, is chief executive officer of the North West LHIN.

Marilyn J. Emery, MScN, CHE, is chief executive officer of the Central East LHIN.

W. Michael Fenn, MA, is former chief executive officer of the Mississauga Halton LHIN.

Sandra J. Hanmer, MHSc, CHE, is chief executive officer of the Waterloo Wellington LHIN.

Paul Huras, MBA, MSc, FCCHSE, is chief executive officer of the South East LHIN.

Mimi Lowi-Young, MHA, FACHE, FCCHSE, is chief executive officer of the Central West LHIN.

Pat Mandy, RN, BA, MPA (PT), is chief executive officer of the Hamilton Niagara Haldimand Brant LHIN.

Jean Trimnell, MScN, CHE, is chief executive officer of the North Simcoe Muskoka LHIN.

Garry Switzer is chief executive officer of the Erie St. Clair LHIN.

Tony Woolgar, MBA, is chief executive officer of the South West LHIN.

John Butler, BA, is president of The Agora Group.

\section{References}

Central East Local Health Integration Network. 2007. Home Page. Ajax, ON: Author. Retrieved April 16, 2007. <http://www.centraleastlhin. on.ca/letterfromchair/letter.html>

Central Local Health Integration Network. 2005. Proposed Provincial LHIN Stakeholder Engagement Strategy Framework. Markham, ON: Author.

Government of Ontario. 2006. Local Health System Integration Act, 2006. Toronto: Author. Retrieved April 16, 2006. <http://www.e-laws. gov.on.ca/DBLaws/Statutes/English/06104_ e.htm>.

Hamilton Niagara Haldimand Brant Local Health Integration Network. 2006. Quality Care in Community Hands: Building an Integrated Health Service Plan, Phase One. Grimsby, ON: Author. Retrieved April 16, 2007. <http://www. hnhblhin.on.ca/web_resources/IHSP/2006/ English/2006-11-30-LHIN-IHSP-ENG-wApp. pdf>.

H. Eliasoph, personal communication, March 2007.

McNiven Consulting. 2006. Integrated Health Service Plans and Community Engagement Strategies: An Initial Review. Author.

North East Local Health Integration Network. 2006. North East Health Integration Network Launches Integrated Health Services Plan Creating Northern Solutions for Northern Health Issues. North Bay, ON: Author. Retrieved April 16, 2007. <http://www.nelhin.on.ca/download/ Dec15_06_Press_IHSPLaunch.pdf>.

Ontario Ministry of Health and Long-Term Care. 2006a. McGuinty Government Launches Public Engagement on Health Care. Toronto: Author. Retrieved April 16, 2007. <http://www. health.gov.on.ca/english/media/news_releases/ archives/nr_06/dec/nr_122006.html>.

Ontario Ministry of Health and Long-Term Care. 2006b. Roadmap to the Integrated Health Service Plan Final Draft. Toronto: Author.

Toronto Central Local Health Integration Network. 2006. 2007-2010 Integrated Health Service Plan. Toronto: Author. Retrieved April 16, 2007. <http://www.torontocentrallhin. on.ca/en/docs/IHSP-ENGLISH_2006.pdf>. 


\title{
Commentary
}

\section{Integrating Health Services: The View from Montreal}

\author{
David Levine
}

It is encouraging to see that the first phase of planning by the LHINs has been done with a lot of enthusiasm and collaboration. The task of integrating healthcare services is not an easy one, and it is made more complicated in Ontario as the key areas that must be well interconnected lie outside the mandate of the LHINs. This being said, I will try to add value to the present article by referring to the integrated planning that is being carried out by the Health and Social Agencies in Quebec.

\section{There is a vision of the way health services should be provided... and it has become a strong unifying force for the region.}

One action taken in the Montreal Agency was to set up a Network Management Committee (NMC) including the CEOs of the local networks. This committee meets every two weeks for a morning to deal with issues of managing and planning the integration of services. Subcommittees have been set up to look at the issues of accessibility, continuity and population health. Meeting this regularly, with $100 \%$ attendance, under the leadership and animation of the agency, has been a team-building experience and has resulted in a very strong regional commitment by each of the CEOs.

A common vision has been put forward by the NMC focused on a population-based model of managed care. This is a vision of the way health services should be provided and the role of each of the providers and the interconnections between them. All activity is based on this common vision, and it has become a strong unifying force for the region. Primary healthcare is the foundation of the vision, and it is essential for the LHINs to be able to include primary care and the health units into their planning process.

The role of animation and leadership must be prominent; though there is no direct management authority of the LHINs or the Montreal Agency over the institutions in their region, there is clearly a need for strong regional leadership to coordinate and integrate services. This leadership requires direct contact with the LHINs and the boards in their region. Each board must be able embrace the common vision and then question its own activities to see if the vision is being applied.

Management and performance contracts between the regional agency and each institution are needed to set targets, measure performance and determine the strategy to implement the regional vision of care. The nature and content of the contracts, the indicators to be used and the targets to be achieved must be agreed upon by all the players so that the contracts become a tool to help implement the vision.

Population-based managed care has been demonstrated as the most successful approach to date, and the setting up of primary care multidisciplinary teams to provide coverage to a registered population is the key. Corridors of service between primary and more complex care must be defined to ensure accessibility and continuity of services.

A clear vision emerging from the LHINs' planning process is the key ingredient to achieving the goal of providing accessible, continuous, highquality care to the population we serve.

\section{About the Author}

David Levine is President and Executive Director, Health and Social Services of Montreal.

\section{Thank you}

for supporting Breakfast with the Chiefs

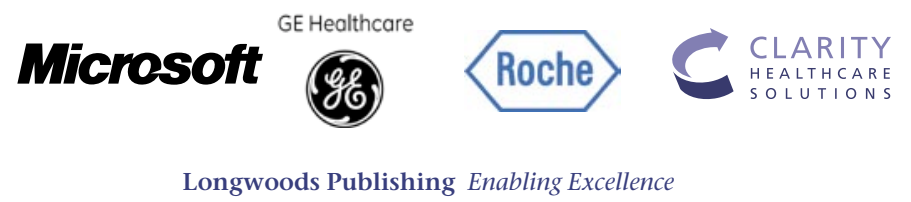




\section{Integrated Health Services Plans: From Planning to Action}

John Ronson

The recent creation of integrated health services plans (IHSPs) by Ontario's 14 regional local health integration networks (LHINs) is an impressive example of collaborative planning, well documented in the lead article. The list of potential areas for improvement in health and healthcare is a long one - and the IHSP process has identified them well. Unfortunately, excellent planning, while an important precursor, does not ensure implementation success. Moving from planning to action is where many welldesigned strategies disintegrate.

Multiple dimensions of traditional healthcare power dynamics must be addressed as LHINs move from planning to implementation. The traditional power bases of hospitals and physicians, largely unthreatened in planning, will move to the forefront during implementation. The "command and control" nature of the Ministry of Health and Long-Term Care must also be neutralized if LHINs are to be successful. Action strategies must be adopted immediately or LHINs will be tempted to retreat to the refuge of yet more planning.

\section{The Dynamics of the IHSP Consultation Process}

The 14 LHINs undertook broad consultation processes as they did their planning. These consultations overrepresented the interests of smaller community-based agencies and under-represented those of physicians and hospitals. Hospitals were often treated as one organization, like any other organization, with little recog- nition that they are generally dominant healthcare providers in their communities. In the case of physicians, many have little patience for long meetings and extended planning exercises. As physicians point out, they are not paid to attend meetings, and the traditional feefor-service compensation system creates adverse incentives to their involvement.

\section{Ontario's chosen healthcare reform route has left boards in place - leaving LHINs with even more players to manage.}

Planning processes are non-threatening - jobs are not lost and incomes are not cut. As the lead article correctly points out, most change will need to be effected through resource reallocation, not the allocation of new funding. Breaking down the traditional healthcare silos and creating a truly integrated system from the patient's perspective will run into massive resistance from powerful forces. Other Canadian provinces dealt with this phenomenon by abolishing hospital and other provider boards by legislative fiat. Ontario's chosen healthcare reform route has left boards in place - leaving LHINs with even more players to manage as they pursue their healthcare integration agendas (Ronson 2006).

The LHIN planning process has raised community expectations. These are legitimate expectations, but they will run headlong into the traditional power bases and financial interests of hospitals and physicians. LHINs must be prepared to address this dynamic, and, just as important, the ministry must be prepared to support LHINs in making tough decisions and in addressing the inevitable "end-runs" to the ministry when decisions are made that offend individual providers and the associations that represent them.

\section{Structural Impediments to Change}

Assuming LHINs are serious about reform, they may have been set up for failure through no fault of their own. The creation of the LHINs is occurring in the context of a broader "transformation" agenda of Ontario's Ministry of Health and Long-Term Care. The ministry is actively working to transform itself from a focus on operations to one of "stewardship" - in other words, from what Osborne and Gaebler (1992) call from "rowing to steering."

The ministry's own transformation appears to be bogged down in labour relations and other bureaucratic impediments. The bureaucratic survival imperative is in full operation. Other provinces embarking on a healthcare regionalization agenda set arbitrary and aggressive targets to downsize the central ministry bureaucracy. In the case of British Columbia, the target, fully achieved, reduced the size of the BC ministry by $50 \%$ of employees in six months. Failure to act with this degree of courage inevitably puts the IHSP agenda at risk. 
LHINs were deliberately structured to be lean and nimble - with no more than 20-25 staff in total. While laudable in concept, this may leave them significantly under-resourced to manage an agenda that encompasses "planning, coordinating, integrating and funding" involving over $\$ 20$ billion annually of healthcare spending. Leaving the ministry over-resourced creates a power imbalance and a temptation on the part of ministry employees to interfere with the legitimate role of the new LHINs. This must be addressed quickly or the LHINs and their ambitious agendas will fail.

\section{Successful implementa- tion requires relentless focus} on results and in a world of constrained resources will result in at least the perception of winners and losers.

\section{LHIN Executive Committee}

One of the early innovations put in place after the LHIN chief executive officers (CEOs) were appointed was regular meetings of the LHIN CEOs and senior ministry officials. This innovation should be extended to give the LHIN CEOs much more control over provincial healthcare agenda setting. This will require a ceding of power by senior ministry officials and their assumption of more of a stewardship role as the LHIN CEOs assume more decision-making authority.

The healthcare information management and information technology (IT) agenda would be an interesting test case. Historically, Ontario has adopted a curious mix of a highly centralized approach to providing information technology infrastructure and applications and a completely hands-off attitude to IM/IT investments by hospitals and other providers. The highly centralized elements have suffered from a track record of poor implementation, including a particular lack of attention to the needs of potential system users (Smart Systems for Health Agency, Ontario 2006). Hospital investments, on the other hand, made without any coordinated planning, have resulted in a patchwork quilt of information systems and no integrated approach to the sharing of clinical records or the realization of efficiencies to be gained by a more coordinated approach.

The LHINs have made a good start on regional IM/IT planning with the development of integrated regional plans (as part of the IHSP development process). Many of these require transparent organizational IM/IT planning as well as coordinated regional IT investments. Concurrently, the LHIN CEOs should be given decision-making control over most central IM/IT investments. This should include control over appointments to the board of directors of the provincial network and application provision organization, the Smart Systems for Health Agency.

\section{Avoiding the Refuge of Planning}

LHINs have already demonstrated through the IHSP process that they are very good at planning. Implementation will be much more difficult. There may be a natural tendency to retreat back to what they know and do best when implementation challenges arise. Is it telling that the first two of the eight priorities identified in the article relate to more planning?

In many respects good implementation is the opposite of good system planning. Good system planning is broad and collaborative. Successful implementation requires relentless focus on results and in a world of constrained resources will result in at least the perception of winners and losers.

\section{Summary}

It will be critical that decision-making be grounded in the public interest, be transparent and evidence based, and put the interests of patients and citizens first. And yes, "We are all in this together." Every citizen coping with a chronic disease or waiting for a surgical procedure should be cautiously optimistic that Ontario's experiment in regional planning can successfully make the shift from excellent planning to excellent implementation.

\section{References}

Osborne, D.E. and T. Gaebler. 1992. Reinventing Government: How the Entrepreneurial Spirit is Transforming the Public Sector. Reading, MA: Addison-Wesley.

Ronson, J. 2006. "Local Health Integration Networks: Will 'Made in Ontario' Work?" Healthcare Quarterly 9(1): 46-49.

Smart Systems for Health Agency, Ontario. 2006. Smart Systems for Health Agency: Operational Review Final Report, November 6, 2006. Toronto: Author. <http://www.ssha. on.ca/operationalreview/index.asp $>$.

\section{About the Author}

John Ronson is a founding partner of Courtyard Group, a global company with offices in Canada, the United States and the United Kingdom that is dedicated to transforming the healthcare system.

\section{Longwoods Review}

Longwoods Review is an integrated section of
Healthcare Quarterly featuring peer-reviewed,
applied research.
Editorial Advisory Board
Philip Berman
Director, European Health Management Association,
Dublin, Ireland
Michael Guerriere, MD, MBA
Managing Partner, Courtyard Group, Toronto, ON
Peggy Leatt, PhD
Professor and Chair, Department of Health Policy and
Administration, Associate Dean for Academic Affairs,
School of Public Health, University of North Carolina at
Chapel Hill
Cam Mustard, ScD
Professor, Department of Public Health Sciences
University of Toronto Faculty of Medicine
President/Scientific Director, Institute for Work \&
Health, Toronto, ON
Dorothy Pringle, PhD
Professor and Dean Emeritus, Faculty of Nursing,
University of Toronto, Toronto, ON
Enrique Ruelas, PhD
Senior Undersecretary, Mexico Health, Mexico City,
Mexico
Eugene Schneller, PhD
Professor and Director, School of Health Administration
\& Policy, Arizona State University, Tempe, AZ

